\title{
Clinical Relevance of Mallampati Grading in Predicting Difficult Intubation in the Era of Various New Clinical Predictors
}

\author{
Mamta Harjai ${ }^{1}$, Sharif Alam ${ }^{1}$, Priyesh Bhaskar ${ }^{2}$ \\ 1. Department of Anesthesiology and Critical Care Medicine, Dr. Ram Manohar Lohia Institute of Medical Sciences, \\ Lucknow, IND 2. Department of Anaesthesiology, Career Institute of Medical Sciences and Hospital, Lucknow, IND
}

Corresponding author: Mamta Harjai, mamtaharjaidoctor@yahoo.co.in

\section{Abstract \\ Background and aims}

Management of difficult airway can be associated with serious morbidity and mortality and it is a basic and serious concern for anesthesiologists. The preoperative airway assessment is done by using conventional clinical predictors. The present study was conducted to find the correlation of various new clinical predictors with the Cormack-Lehane (CL) grade at the laryngoscopic view in patients undergoing general anesthesia with endotracheal intubation.

\section{Settings and design}

The prospective, comparative, observational, double-blind study was carried at Dr. Ram Manohar Lohia Institute of Medical Sciences, Lucknow.

\section{Materials and methods}

The study was conducted in 150 patients undergoing elective surgery under general anaesthesia. The primary outcome was the measurement of clinical airway assessment preoperatively based on certain parameters (inter incisor gap (IIG), modified Mallampati grading (MPG), neck circumference/thyromental distance (NC/TMD), ratio of height to thyromental distance (RHTMD)). The secondary outcome was the correlation of clinical airway assessment with CL grading to predict difficult intubation. The sensitivity, specificity, positive predictive value (PPV), and negative predictive values (NPV) of the parameters were assessed.

\section{Statistical analysis}

The association between different predictors and difficult laryngoscopy was evaluated using binary univariate logistic regression and multivariate logistic regression and the significant clinical predictors were assessed by using Pearson's correlation. A p-value of $<0.05$ was considered significant.

Review began 05/30/2021 Review ended 07/05/2021 Published 07/14/2021

\section{(c) Copyright 2021}

Harjai et al. This is an open access article distributed under the terms of the Creative Commons Attribution License CC-BY 4.0., which permits unrestricted use, distribution, and reproduction in any medium, provided the original author and source are credited.

\section{Results}

The incidence of difficult intubation in this study was $13.3 \%$. Among the clinical predictors, the Mallampati grading has the maximum receiver operating characteristic (ROC) and area under the curve (AUC) with 86.7 $\%$ sensitivity to predict difficult laryngoscopy followed by NC/TMD and body mass index.

\section{Conclusion}

Modified Mallampati grading still holds its significant value among new predictors in the assessment of difficult laryngoscopy.

Categories: Anesthesiology, Emergency Medicine, Trauma

Keywords: airway, cormack-lehane grade, endotracheal intubation, general anesthesia, laryngoscopy

\section{Introduction}

The first major responsibility for the anesthesiologist is to provide adequate ventilation and oxygenation by securing the patient's airway. Preoperative assessment of the patient's airway facilitates the anesthesiologists to predict the ease of visualizing the glottis and to perform intubation easily. Various studies have shown the incidence of difficult intubation ranging between $9 \%$ and $16 \%[1,2]$ while the incidence of difficult intubation in the intensive care unit (ICU) or Emergency Medicine Department is probably as high as $20 \%$ [3]. Though there are several conventional clinical airway assessment parameters such as the modified Mallampati classification [4,5], hyomental distance, thyromental distance, neck movements, inter incisor gap, BMI, and ability to flex and extend the cervical spine, neck circumference, 
upper lip bite test, etc. which are usually used to predict a difficult airway preoperatively [6], the diagnostic accuracy of these predictors in predicting difficult intubation is low during pre-anesthetic airway assessment [7] and unexpected difficult intubations continue to occur. The diagnostic accuracy of these pre-anesthetic airway screening tests has varied from study to study [8]. Recently new clinical predictors like neck circumference/thyromental distance (NC/TMD), ratio of height to thyromental distance (RHTMD) have been studied in detail $[9,10]$. The primary aim of our study was to evaluate sensitivity, specificity, positive predictive value (PPV), negative predictive value (NPV), odds ratio (OR), and receiver operating characteristic (ROC) for various conventional clinical screening tests such as Mallampati grade (MPG), inter incisor gap (IIG), Mentohyoid distance, thyromental distance (TMD), neck circumference (NC), NC/TMD, RHTMD, to determine a precise as well as simple and clinically relevant parameter among conventional and new ones for predicting difficult laryngoscopy for regular practice in anesthesia to reduce the airway-related morbidity and mortality.

\section{Materials And Methods}

After getting approval from Ethical Committee (IEC no.77/17, CTRI/2019/02/017508), Dr .Ram Manohar Lohia Institute of Medical Sciences, Lucknow, UP, this prospective, comparative, observational and doubleblind study was conducted. The study included 150 patients of ASA grade 1 and 2, aged 18-65 years, either sex without any known obvious airway pathology undergoing elective surgery under general anesthesia for 12-15 months. Informed consent was taken from all the patients. Patients who refused to give consent or patients with any feature of the obvious difficult airway due to facial anomalies, obesity (body mass index $[\mathrm{BMI}]>35 \mathrm{~kg} / \mathrm{m}^{2}$ ), limited mouth opening and patients requiring rapid sequence intubation, with cervical spine pathology, uncooperative patients and pregnant patients were excluded from the study.

All patients underwent a detailed preoperative airway evaluation on the day before surgery by the anesthesiologist who was blinded to the study. The modified MPG, IIG, mentohyoid distance, TMD, NC, BMI, NC/TMD, RHTMD were noted and recorded for all patients.

Modified MPG [11] was done to assess the oropharyngeal view by asking the patient to sit and open his/ her mouth maximally and to protrude the tongue without phonation and record the structures visible upon maximal mouth opening and classified as score. Score 1 is when soft palate, fauces, uvula, and tonsillar pillars clearly visible, Score 2 is soft palate, fauces, and the uvula visible, Score 3 is soft palate and base of the uvula visible and Score 4 is when soft palate not visible.

IIG was assessed by measuring the space between the upper and lower incisors at the midline asking each patient to open the mouth to the maximum possible. The normal distance is typically $>3.5 \mathrm{~cm}$ [12].

Mentohyoid distance was measured as the distance between the hyoid bone and the tip of the chin when the head was fully extended and the mouth closed. The normal distance is $>5.3 \mathrm{~cm}$.

TMD was measured as a distance from the thyroid notch to the mentum while the head was fully extended and mouth closed, employing a rigid ruler. The distance was rounded to the closest $0.5 \mathrm{~cm}$ and graded as, Class I: $>6.5 \mathrm{~cm}$, Class II: $6-6.5 \mathrm{~cm}$ and Class III: $<6 \mathrm{~cm}$. NC was measured at the level of the cricoid cartilage. The NC/TMD and RHTMD [13] were then calculated.

After preoperative assessments, on the day of surgery, the patient was shifted to the operating room with intravenous access. All standard monitors like ECG, noninvasive blood pressure (NIBP), pulse oximetry, temperature probe were connected and values noted. After preoxygenation of three to five minutes, IV midazolam (0.05-0.15 mg/kg) and IV fentanyl $(2 \mu \mathrm{g} / \mathrm{kg})$ were administered as premedication. The patients were induced by IV induction agent, IV propofol $(2 \mathrm{mg} / \mathrm{kg})$. After three minutes of administration of IV muscle relaxant Inj rocuronium $(0.6-0.8 \mathrm{mg} / \mathrm{kg})$, all patients were intubated by the senior anesthesiologist who had the experience of more than three years and was blinded to the findings of preoperative airway assessment. Direct laryngoscopy was performed using Macintosh blade. Glottic visualization was assessed and Cormack-Lehane (CL) grade was noted as Grade I when full glottic exposure was seen, while it was Grade II when only posterior commissure of glottis was seen, Grade III was only epiglottis visible and Grade IV when epiglottis was not even visible.

Intubation was classified as easy Laryngoscopy (CL Grade 1 and 2) and difficult laryngoscopy (CL Grade 3 and 4) characterised by poor glottic visualization. To preclude the bias in the results due to demand characteristics or the placebo effect, double-blind procedure was utilized in the study.

\section{Statistical analysis}

Statistical analysis was performed using commercially available computer software IBM SPSS software version 21 for windows IBM Corp., Armonk, NY, USA. Sample size was calculated on the assumption of incidence of difficult intubation as $10 \%[1,2]$ as seen in previous studies. Type 1 error was set at $4 \% .138$ patients provide a power of $>80 \%$ to predict co-relation between the CL grading and the clinical predictors with a type I error of $3 \%$. We enrolled 150 patients. Patient data were presented as mean \pm standard 


\section{Cureus}

deviation.

\section{Results}

Total of 150 patients were recruited into our study, which included 64 men (42.7\%) and 86 women (57.3\%), with age ranging from 18 to 65 years. The incidence of poor visualization of larynx during laryngoscopy in our study was $13.3 \%$ (20 patients) and incidence of good visualization of larynx was $86.7 \%$ (130 patients). There were no patients in the extremely difficult group (CL Grade IV). Table 1 shows the distribution of the patients according to the CL grade at direct laryngoscopy. 77 patients had a CL Grade I (51.3\%), 53 patients had a CL Grade II (35.3\%), 20 patients had a CL Grade III (13.3\%), and none of the patients had a CL Grade IV.

\begin{tabular}{|c|c|c|c|}
\hline CL grade & Visualization & Frequency & Percent \\
\hline 1.0 & Full glottic exposure & 77 & 51.3 \\
\hline 2.0 & Only posterior commissure of glottis seen & 53 & 35.3 \\
\hline 3.0 & Only epiglottis visible & 20 & 13.3 \\
\hline 4.0 & Epiglottis not visible & None & 0 \\
\hline Total & & 150 & 100.0 \\
\hline
\end{tabular}

TABLE 1: Data demonstrating Cormack-Lehane (CL) score of patients.

The demographic profile, including age, sex, weight, height and BMI of easy and difficult laryngoscopy are shown in Table 2. Difference in age and height of patients of both groups were not found to be statistically significant, the male and female ratio was comparable in both easy and difficult laryngoscopy groups, while the difference in weight and BMI were found to be statistically significant $(\mathrm{p}=0.005)$ when both groups were compared. Mean BMI of patients in easy laryngoscopy group was $24.31 \pm 3.8 \mathrm{~kg} / \mathrm{mt} 2$ and $27.42 \pm 4.72 \mathrm{~kg} / \mathrm{mt} 2$ in difficult laryngoscopy group.

\begin{tabular}{|c|c|c|c|c|c|}
\hline \multirow{2}{*}{ Parameters } & \multicolumn{2}{|c|}{ Easy $(C L 1-2)(n=130)$} & \multicolumn{2}{|c|}{ Difficult (CL 3-4) $(n=20)$} & \multirow{2}{*}{${ }^{1} p$-value } \\
\hline & Mean & $\pm \mathrm{SD}$ & Mean & $\pm \mathrm{SD}$ & \\
\hline Age (year) & 43.75 & 12.24 & 47.90 & 10.61 & 0.154 \\
\hline Sex: Male & 57 & $43.85 \%$ & 7 & $35 \%$ & \\
\hline Female & 73 & $56.15 \%$ & 13 & $65 \%$ & 0.720 \\
\hline Weight (kg) & 61.46 & 11.31 & 67.30 & 7.67 & $0.027^{*}$ \\
\hline Height (cm) & 158.72 & 8.10 & 157.65 & 10.38 & 0.599 \\
\hline BMI $\left(\mathrm{kg} / \mathrm{m}^{2}\right)$ & 24.31 & 3.80 & 27.015 & 4.72 & $0.005^{*}$ \\
\hline
\end{tabular}

TABLE 2: Demographic data of the easy and difficult laryngoscopy groups.

${ }^{1}$ Binary univariate logistic regression. *Significant $p$ value $(p<0.05)$. CL: Cormack-Lehane.

The American Society of Anesthesiologists (ASA) grade I and II were comparable in both easy and difficult laryngoscopy. Clinical airway predictors like MPG, IIG, mentohyoid distance, TMD, NC, NC/TMD, RHTMD, were measured to anticipate laryngoscopy based on Cormack and Lehane's view as shown in Table 3. Out of 150 patients, 37 had MPG score I (28.46\%), 76 (58.46\%) with score II, 17 (13.08\%) were found to have score III in easy group whereas 1 (5\%) patient had MPG score I, 12 (60\%) with score II, 4 (20\%) with score III and 3 (15\%) patients had score IV in difficult group. The MPG grade III and IV were found to be a strong predictor in anticipating difficult airway $(\mathrm{p}<0.001)$, while the difference in inter incisor gap of patients of easy and difficult laryngoscopy group was found to be statistically significant $(\mathrm{p}<0.001)$. The difference in mentohyoid distance, TMD, NC, NC/TMD and RHTMD of patients of easy and difficult laryngoscopy was not found to be statistically significant $(\mathrm{p}<0.378$ and $\mathrm{p}<0.096, \mathrm{p}=0.223, \mathrm{p}=0.062$ and $\mathrm{p}=0.253$, respectively). Mean NC/TMD in patients of easy and difficult group was $3.802 \pm 0.53 \mathrm{~cm}$ and $4.04 \pm 0.44 \mathrm{~cm}$, respectively. 


\section{Cureus}

\begin{tabular}{|c|c|c|c|c|c|}
\hline \multirow{2}{*}{ Parameters } & \multicolumn{2}{|c|}{ Easy $(C L 1-2)(n=130)$} & \multicolumn{2}{|c|}{ Difficult (CL 3-4) $(n=20)$} & \multirow{2}{*}{${ }^{1} p$-value } \\
\hline & $\mathrm{N}$ & $\%$ & $\mathrm{~N}$ & $\%$ & \\
\hline ASA I & 50 & 38.46 & 7 & 35 & 0.752 \\
\hline ASA II & 80 & 61.54 & 13 & 65 & \\
\hline MPG Score 1 & 37 & 28.46 & 1 & 5 & \\
\hline 2 & 76 & 58.46 & 12 & 60 & \\
\hline 3 & 17 & 13.08 & 4 & 20 & $<0.001^{*}$ \\
\hline \multirow[t]{2}{*}{4} & 0 & 0.00 & 3 & 15 & $<0.001^{*}$ \\
\hline & Mean & $\pm \mathrm{SD}$ & Mean & $\pm \mathrm{SD}$ & \\
\hline Inter incisor gap & 4.80 & 0.65 & 4.08 & 0.90 & $<0.001^{\star}$ \\
\hline Mentohyoid distance & 5.36 & 0.77 & 5.20 & 0.69 & 0.378 \\
\hline Thyromental distance (TMD) & 9.43 & 1.08 & 9.01 & 0.61 & 0.096 \\
\hline Neck circumference (NC) & 35.43 & 3.90 & 36.55 & 3.02 & 0.223 \\
\hline NC/TMD & 3.80 & 0.53 & 4.04 & 0.44 & 0.062 \\
\hline Ratio of height to thyromental distance (RHTMD) & 17.07 & 1.82 & 17.54 & 1.30 & 0.253 \\
\hline
\end{tabular}

TABLE 3: Clinical Parameters of the easy and difficult laryngoscopy groups according to binary univariate logistic regression analysis.

${ }^{1}$ Binary univariate logistic regression. *Significant $p$ value $(p<0.05)$. CL: Cormack-Lehane; ASA: American Society of Anesthesiologists.

The binary multivariate logistic regression was also used for analysis in BMI $\left(\mathrm{kg} / \mathrm{m}^{2}\right), \mathrm{MPG}$, IIG, mentohyoid distance, TMD, NC, NC/TMD, RHTMD, to determine the risk factors for difficult laryngoscopy as shown in Table 4. The IIG, TMD, NC and NC/TMD were found to be a significant independent risk factor for laryngoscopy.

\begin{tabular}{|c|c|c|c|c|c|c|c|}
\hline \multirow{2}{*}{ Variables } & \multirow{2}{*}{$\boldsymbol{\beta}$} & \multirow{2}{*}{ SE } & \multirow{2}{*}{ Wald } & \multirow{2}{*}{ p-value } & \multirow{2}{*}{ OR } & \multicolumn{2}{|c|}{$95 \% \mathrm{Cl}$} \\
\hline & & & & & & Lower & Upper \\
\hline BMI $\left(\mathrm{kg} / \mathrm{m}^{2}\right)$ & 0.158 & 0.160 & 0.973 & 0.324 & 1.171 & 0.855 & 1.604 \\
\hline Mallampati grade & 0.755 & 0.783 & 0.931 & 0.335 & 2.128 & 0.459 & 9.866 \\
\hline Inter incisor gap & -2.317 & 0.819 & 7.995 & $0.005^{\star}$ & 0.099 & 0.020 & 0.491 \\
\hline Mentohyoid distance & -1.131 & 0.794 & 2.032 & 0.154 & 0.323 & 0.068 & 1.528 \\
\hline Thyromental distance (TMD) & -18.266 & 6.487 & 7.928 & $0.005^{\star}$ & - & - & 0.004 \\
\hline Neck circumference (NC) & 4.737 & 1.666 & 8.089 & $0.004^{*}$ & 114.139 & 4.361 & 2987.00 \\
\hline NC/TMD & -35.90 & 13.219 & 7.378 & $0.007^{*}$ & - & - & - \\
\hline Ratio of height to thyromental distance (RHTMD) & -0.936 & 0.603 & 2.407 & 0.121 & 0.392 & 0.120 & 01.279 \\
\hline
\end{tabular}

TABLE 4: Binary multivariate logistic regression (forward-Wald) analysis performed in each patient group to determine the independent risk factors for difficult laryngoscopy in each population. 
Based on the ROC curve, the area under the curve (AUC) of BMI, MPG, IIG, mentohyoid distance, TMD, NC, NC/TMD and RHTDM were $0.670,0.690,0.268,0.439,0.376,0.602,0.679$ and 0.592 , respectively as shown in Table 5 .

\begin{tabular}{|c|c|c|c|c|c|}
\hline & \multirow{2}{*}{ Area } & \multirow{2}{*}{ SE } & \multirow{2}{*}{ p-value } & \multicolumn{2}{|l|}{$95 \% \mathrm{Cl}$} \\
\hline & & & & Lower bound & Upper bound \\
\hline BMI $\left(\mathrm{kg} / \mathrm{m}^{2}\right)$ & 0.670 & 0.063 & 0.014 & 0.5477 & 0.93 \\
\hline Mallampati grade & 0.690 & 0.062 & 0.006 & 0.568 & 0.812 \\
\hline Inter incisor gap & 0.268 & 0.061 & 0.001 & 0.149 & 0.388 \\
\hline Mentohyoid distance & 0.439 & 0.075 & 0.379 & 0.293 & 0.585 \\
\hline Thyromental distance (TMD) & 0.376 & 0.058 & 0.075 & 0.263 & 0.490 \\
\hline Neck circumference (NC) & 0.602 & 0.058 & 0.144 & 0.488 & 0.715 \\
\hline NC/TMD & 0.679 & 0.054 & 0.010 & 0.573 & 0.785 \\
\hline Ratio of height to thyromental distance (RHTMD) & 0.592 & 0.059 & 0.185 & 0.476 & 0.708 \\
\hline
\end{tabular}

TABLE 5: Receiver operating characteristic (ROC) analysis of difficult laryngoscopy components and BMI, Mallampati grade, inter incisor gap, mentohyoid distance, thyromental distance (TMD), neck circumference (NC), NC/TMD and RHTMD.

In this test, maximum AUC was found in MPG followed by NC/TMD and BMI. The AUC for the modified Mallampati class was 0.690 among the clinical predictors indicating that it has the highest validity among the parameters studied. The sensitivity, specificity, NPV and PPV were used to analyze the Mallampati grade, Inter incisor gap, Mentohyoid distance, (Table 6). These tests were done to demonstrate the accuracy of risk factors. The cut-off points for difficult laryngoscopy were the Mallampati score $\geqslant 3$, Inter incisor gap $<3.8$, and Mentohyoid distance <5.26. Among these clinical predictors, the inter incisor gap was most sensitive (sensitivity of 89.3 ) and most specific (specificity of 50\%) in predicting difficult laryngoscopy but PPV was $96.2 \%$ and NPV $25 \%$ as compared to Mallampati score which showed PPV and NPV as $100 \%$.

\begin{tabular}{|c|c|c|c|c|}
\hline Test & Sensitivity & Specificity & PPV & NPV \\
\hline Mallampati Score & $86.7 \%$ & $13.3 \%$ & $100.0 \%$ & $100.0 \%$ \\
\hline Inter incisor gap & $89.3 \%$ & $50.0 \%$ & $96.2 \%$ & $25.0 \%$ \\
\hline Mentohyoid distance & $83.0 \%$ & $4.5 \%$ & $67.7 \%$ & $10.0 \%$ \\
\hline
\end{tabular}

TABLE 6: Sensitivity, specificity, positive predictive value (PPV), and negative predictive value (NPV) of the conventional clinical parameters in predicting a difficult laryngoscopy.

\section{Discussion}

Difficult airway is the major factor of mortality and morbidity following anesthesia and is generally encountered during unexpected clinical conditions [14]. Though the use of video laryngoscopic devices and supraglottic airway devices has increased, direct laryngoscopy is still most frequently used as the first device for intubation. It remains a challenge to date to identify the patients in whom laryngoscopy and intubation may be difficult. Several studies in different clinical fields have been conducted to identify predictors of difficult laryngoscopy and intubation [15-17].

Demographic data (age and sex distribution) was comparable between easy and difficult laryngoscopy during intubation. Among clinical predictors for difficult airway assessment, the weight of patients showed a significant difference in easy and difficult laryngoscopy $(\mathrm{p}=0.027)$. BMI $\left(\mathrm{kg} / \mathrm{m}^{2}\right)$ was also associated with difficult airway $(\mathrm{p}=0.005)$. This finding was supported by another study by Helene Gonzalez et al [18] who found that difficult tracheal intubation was more frequent in obese than in lean patients $(14.3 \%$ vs $3 \%$; $=$ 
0.03). Increase in fat distribution specifically in the anterior neck in patients of high BMI might be a relevant predictor of difficult intubation in this subset of patients [18].

The MPG grade (III \& IV) was found to be highly statistically significant $(\mathrm{p}<0.001)$ in the present study for the easy and difficult intubation. The Mallampati test, when considered as a single predictor for difficult laryngoscopy had a sensitivity of $86.7 \%$. Previous studies which have used Mallampati as a single predictor had a wide range of sensitivity from $40 \%$ to $82.4 \%[6,11,19]$ which could be attributed to the inter-observer variability for assessing MPG grading. In our study, the tests were carried out by the same investigator, thereby avoiding inter-observer variability.

In our study, another clinical predictor that was found to be statistically significant $(\mathrm{p}<0.001)$ was the inter incisor gap. Wilson et al. [12] in their study showed that the inter incisor gap was significantly smaller in those patients where laryngoscopy was difficult. Our findings were in accordance with another study done by Abdel Raouf et al. [20] who concluded that inter incisor gap $<4 \mathrm{~cm}$ was associated with difficult laryngoscopy. Insertion of laryngoscope or airway devices in patients with less inter incisor gap obscures the vision of the larynx.

The other parameters like mentohyoid distance, TMD, NC were not found to be significant independent predictors. In the present study, the mento hyoid distance was measured in neutral position in spite of measuring in the position in which laryngoscopic intubation is actually performed. The diagnostic value of TMD was found to be unsatisfactory as an individual predictor in Meta-analysis performed by Shiga et al. [17]. It has been observed in many previous studies [21], that neck circumference of obese patients was found to have significant effects on difficult intubation at $40 \mathrm{~cm}$ of neck circumference, the probability of difficult intubation was approximately $5 \%$, and at $60 \mathrm{~cm}$ of neck circumference, the probability of difficult intubation was approximately $35 \%$ and concluded that increase in neck circumference was associated with difficult intubation in obese patients [22]. The disparity in the present study and study done by others can be explained by the exclusion criteria of the present study which did not include the patients with BMI $>35$ $\mathrm{kg} / \mathrm{mt} 2$. The Neck Circumference is not a perfect indicator alone because the amount of soft tissue at the various region of neck is different [23]. But when multivariate binary logistic regression analysis was used, we found that neck circumference was statistically significant to differentiate between easy and difficult laryngoscopy with $\mathrm{p}=0.004$.

The difference in NC/TMD of patients of easy and difficult laryngoscopy was not found to be statistically significant $(\mathrm{p}=0.062)$ during univariate logistic regression analysis. This is because, in the present study, we did not found NC or TMD as a significant predictor and patients with a value of NC/TMD $>5 \mathrm{~cm}$ was seen in only 6 patients out of 150 . But on using binary multivariate logistic regression analysis (Table 4) to determine the independent risk factors for difficult laryngoscopy, we get NC/TMD as a statistically significant ( $p=0.007$ ) factor. Sangeeta D et al. [23], Yadav et al. [24] and Rajani et al. [25] also found NC/TMD as a significant predictor in their study.

In the present study, RHTMD was not found to be statistically significant $(\mathrm{p}=0.253)$. Our study found the maximum value of RHTMD as 22.67. The result was not in accordance with the various studies like Schmitt et al [26] (cut off of RHTMD>25) and Krobbuaban et al [27] (cut off of RHTMD>23.5) who concluded that RHTMD was a good predictor for difficult laryngoscopy. Azim et al [10] also found high sensitivity with RHTMD (64.7\%) and interpreted it to be a simple preoperative test for screening. In another Indian study [28], authors demonstrated that the RHTMD can also be used as an acceptable alternative for better airway predictability other than ULBT which can be used as a simple bedside screening tool for prediction of difficulty during intubation, but it should always be combined with other airway assessment tests.

The IIG has been demonstrated to be one of the most sensitive single predictors of a difficult airway in normal patients $[12,20,29]$. This is in accordance to our study where the maximum sensitivity and specificity was observed in IIG while in another recent study done by Yong-Zheng Han et al. [30] the ratio of NC and IIG (RNIIG) was found to be a new and simple predictor with a higher level of efficacy, and they suggested that it could help in better management of difficult laryngoscopy specially in patients with cervical spondylosis.

ROC curve was obtained for various clinical variables. ROC Curve is a statistical graph to represent the sensitivity and specificity of any test and the AUC is an effective measure for assessing the inherent validity of the test and it will help to know to what extent the test is diagnostic. Diagnostic accuracy is directly proportional to the area under the curve. In our study, the AUC was found maximum in Mallampati grade (0.690) followed by NC/TMD and BMI indicating that these may be used for bedside screening tests for determination of difficult laryngoscopy. Hence, MPG with $86.7 \%$ sensitivity, maximum ROC and maximum AUC can be a good predictor of difficult laryngoscopy. By assessing and comparing the results obtained from all the above-mentioned clinical tests, we found that each one has its advantages and disadvantages and all variables showed large indecisive results that may explain previous inconsistent results in the prediction of difficult laryngoscopy so combination of these predictors rather than single one can be more helpful in anticipation of difficult intubation beforehand. 


\section{Limitations of study}

The sample size of our study may be small and a larger study is warranted for confirmation of the findings. Secondly, there were some extra variables that were difficult to control like position used during intubation, number of attempts at laryngoscopy and intubation, the view of glottis used during Cormack-Lehane's grading (though we tried to minimize this by including the best view as the first view or the view just before passing the endotracheal tube) . However, we took all precautions to minimize these factors. We tried to decrease inter-observer variability bias by keeping the same person for observation of clinical parameters.

\section{Conclusions}

In conclusion, we found that several airway assessment parameters IIG, TMD and NC/TMD were statistically significant independent risk factors for difficult laryngoscopy. But MPG along with inter incisor gap still holds its significant value as a single, simple bedside predictor among new predictors in assessment of difficult airway. Combining it with other single valuable predictors will increase the probability of correct diagnosis. Further studies with tests which may involve combination of two or more simple bedside predictors to device a simple airway assessment tool are warranted for best clinical results.

\section{Additional Information \\ Disclosures}

Human subjects: Consent was obtained or waived by all participants in this study. Dr Ram Manohar Lohia Institute of Medical Sciences issued approval IEC no.77/17. APPROVED. Animal subjects: All authors have confirmed that this study did not involve animal subjects or tissue. Conflicts of interest: In compliance with the ICMJE uniform disclosure form, all authors declare the following: Payment/services info: All authors have declared that no financial support was received from any organization for the submitted work. Financial relationships: All authors have declared that they have no financial relationships at present or within the previous three years with any organizations that might have an interest in the submitted work. Other relationships: All authors have declared that there are no other relationships or activities that could appear to have influenced the submitted work.

\section{Acknowledgements}

We are thankful to our patients, who wholeheartedly participated in this research.

\section{References}

1. Workeneh SA, Gebregzi AH, Denu ZA: Magnitude and predisposing factors of difficult airway during induction of general anaesthesia. Anesthesiol Res Pract. 2017, 2017:5836397. 10.1155/2017/5836397

2. Martin LD, Mhyre JM, Shanks AM, Tremper KK, Kheterpal S: 3,423 emergency tracheal intubations at a university hospital: airway outcomes and complications. Anesthesiology. 2011, 114:42-8. 10.1097/ALN.0b013e318201c415

3. Karalapillai D, Darvall J, Mandeville J, Ellard L, Graham J, Weinberg L: A review of video laryngoscopes relevant to the intensive care unit. Indian J Crit Care Med. 2014, 18:442-52. 10.4103/0972-5229.136073

4. Mallampati SR: Clinical sign to predict difficult tracheal intubation (hypothesis) . Can Anaesth Soc J. 1983, 30:316-7. 10.1007/BF03013818

5. Mallampati SR, Gatt SP, Gugino LD, Desai SP, Waraksa B, Freiberger D, Liu PL: A clinical sign to predict difficult tracheal intubation: a prospective study. Can Anaesth Soc J. 1985, 32:429-34. 10.1007/BF03011357

6. Karkouti K, Rose DK, Wigglesworth D, Cohen MM: Predicting difficult intubation: a multivariable analysis . Can J Anaesth. 2000, 47:730-9. 10.1007/BF03019474

7. Khan ZH, Mohammadi M, Rasouli MR, Farrokhnia F, Khan RH: The diagnostic value of the upper lip bite test combined with sternomental distance, thyromental distance, and interincisor distance for prediction of easy laryngoscopy and intubation: a prospective study. Anesth Analg. 2009, 109:822-4. 10.1213/ane.0b013e3181af7fod

8. Nørskov AK, Rosenstock CV, Wetterslev J, Astrup G, Afshari A, Lundstrøm LH: Diagnostic accuracy of anaesthesiologists' prediction of difficult airway management in daily clinical practice: a cohort study of 188064 patients registered in the Danish Anaesthesia Database. Anaesthesia. 2015, 70:272-81. 10.1111/anae. 12955

9. Kim WH, Ahn HJ, Lee CJ, Shin BS, Ko JS, Choi SJ, Ryu SA: Neck circumference to thyromental distance ratio: a new predictor of difficult intubation in obese patients. Br J Anaesth. 2011, 106:743-8. 10.1093/bja/aer024

10. Honarmand A, Safavi M, Yaraghi A, Attari M, Khazaei M, Zamani M: Comparison of five methods in predicting difficult laryngoscopy: Neck circumference, neck circumference to thyromental distance ratio, the ratio of height to thyromental distance, upper lip bite test and Mallampati test. Adv Biomed Res. 2015, 4:122. 10.4103/2277-9175.158033

11. Samsoon GL, Young JR: Difficult tracheal intubation: a retrospective study. Anaesthesia. 1987, 42:487-90. 10.1111/j.1365-2044.1987.tb04039.x

12. Wilson ME, Spiegelhalter D, Robertson JA, Lesser P: Predicting difficult intubation. Br J Anaesth. 1988, 61:211-6. 10.1093/bja/61.2.211

13. Schmitt, H. J., Kirmse, M., \& Radespiel-Troger, M. : Ratio of patient's height to thyromental distance improves prediction of difficult laparoscopy. Anaesth Intensive Care. 2002, 30:763-5. 10.1177/0310057x0203000607

14. Cook TM, MacDougall-Davis SR: Complications and failure of airway management. Br J Anaesth. 2012, 
109:i68-85. 10.1093/bja/aes393

15. Apfelbaum JL, Hagberg CA, Caplan RA, et al.: Practice guidelines for management of the difficult airway: an updated report by the American Society of Anesthesiologists Task Force on Management of the Difficult Airway. Anesthesiology. 2013, 118:251-70. 10.1097/ALN.0b013e31827773b2

16. Cattano D, Panicucci E, Paolicchi A, Forfori F, Giunta F, Hagberg C: Risk factors assessment of the difficult airway: an italian survey of 1956 patients. Anesth Analg. 2004, 99:1774-9. 10.1213/01.ANE.0000136772.38754.01

17. Shiga T, Wajima Z, Inoue T, Sakamoto A: Predicting difficult intubation in apparently normal patients: a meta-analysis of bedside screening test performance. Anesthesiology. 2005, 103:429-37. 10.1097/00000542200508000-00027

18. Gonzalez H, Minville V, Delanoue K, Mazerolles M, Concina D, Fourcade O: The importance of increased neck circumference to intubation difficulties in obese patients. Anesth Analg. 2008, 106:1132-6. 10.1213/ane.0b013e3181679659

19. Tse JC, Rimm EB, Hussain A: Predicting difficult endotracheal intubation in surgical patients scheduled for general anesthesia: a prospective blind study. Anesth Analg. 1995, 81:254-8. 10.1097/00000539-19950800000008

20. El-Ganzouri AR, McCarthy RJ, Tuman KJ, Tanck EN, Ivankovich AD: Preoperative airway assessment: predictive value of a multivariate risk index. Anesth Analg. 1996, 82:1197-204. 10.1097/00000539199606000-00017

21. Karna AK, Bashir K: Relationship of neck circumference and difficult endotracheal intubation in obese patients. Janaki Medical Coll J Med Sci . 2016, 4:3-9. 10.3126/jmcjms.v4i2.17070

22. Brodsky JB, Lemmens HJ, Brock-Utne JG, Vierra M, Saidman LJ: Morbid obesity and tracheal intubation. Anesth Analg. 2002, 94:732-6. 10.1097/00000539-200203000-00047

23. Dhanger S, Gupta SL, Vinayagam S, Bidkar PU, Elakkumanan LB, Badhe AS: Diagnostic accuracy of bedside tests for predicting difficult intubation in Indian population: an observational study. Anesth Essays Res. 2016, 10:54-8. 10.4103/0259-1162.165503

24. Yadav BB, Mishra V, Bogra J, Agarwal A, Rai S, Prakash A: Evaluation of modified Mallampati score with neck circumference and thyromental distance to predict difficult intubation in non-obese patients. Int J Contemp Med Res. 2019, 6:C16-C20. 10.21276/ijcmr.2019.6.3.26

25. Rajani BR, Saraswala MB, Gupta SC: Diagnostic value of different screening tests for predicting difficult intubation. Medpulse Int J Anesthesiol. 2019, 9:216-21.

26. Schmitt HJ, Kirmse M, Radespiel-Troger M: Ratio of patient's height to thyromental distance improves prediction of difficult laryngoscopy. Anaesth Intensive Care. 2002, 30:763-5. 10.1177/0310057X0203000607

27. Krobbuaban B, Diregpoke S, Kumkeaw S, Tanomsat M: The predictive value of the height ratio and thyromental distance: four predictive tests for difficult laryngoscopy. Anesth Analg. 2005, 101:1542-5. 10.1213/01.ANE.0000181000.43971.1E

28. Badheka JP, Doshi PM, Vyas AM, Kacha NJ, Parmar VS: Comparison of upper lip bite test and ratio of height to thyromental distance with other airway assessment tests for predicting difficult endotracheal intubation. Indian J Crit Care Med. 2016, 20:3-8. 10.4103/0972-5229.173678

29. Yildiz TS, Solak M, Toker K: The incidence and risk factors of difficult mask ventilation . J Anesth. 2005, 19:7-11. 10.1007/s00540-004-0275-Z

30. Han YZ, Tian Y, Xu M, Ni C, Li M, Wang J, Guo XY: Neck circumference to inter-incisor gap ratio: a new predictor of difficult laryngoscopy in cervical spondylosis patients. BMC Anesthesiol. 2017, 17:55. 10.1186/s12871-017-0346-y 